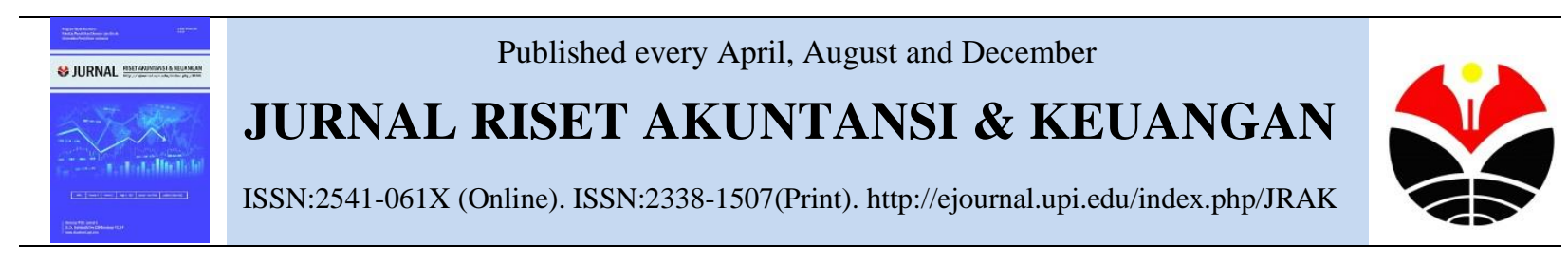

\title{
Sistem Informasi Dilihat dari Aspek Kualitas Informasi Akuntansi Manajemen
}

\author{
Rima Rachmawati \\ Program Studi Akuntansi, FEB, Universitas Widyatama, Bandung, Indonesia
}

\begin{abstract}
Management accounting information is generated by management accounting information systems. A quality information system capable of producing quality management accounting information. Information systems are measured by attributes; Integration, flexibility, accessibility, formalization and richness media. While management accounting information is measured by attribute; Scope, timeliness, accuracy, format and relevancy. This study aims to measure how much influence the quality of management accounting information systems to the quality of management accounting information. This research uses survey method, is descriptive and verification. Unit of analysis at the ITB Personnel Directorate. Data analysis using regression equation. The results showed that the quality of management accounting information systems affect the quality of management accounting information size variability of management accounting information quality is explained by the variable quality of management accounting information system of $98.6 \%$.
\end{abstract}

Keyword: Accounting Information Systems; Management Accounting Information; Management Accounting

Abstrak. Informasi akuntansi manajemen dihasilkan oleh sistem informasi akuntansi manajemen. Sistem informasi yang berkualitas yang mampu menghasilkan informasi akuntansi manajemen yang berkualitas. Sistem informasi diukur dengan atribut: integration, flexibility, accessibility, formalization dan media richness. Sedangkan informasi akuntansi manajemen diukur dengan atribut: scope, timeliness, accuracy, format dan relevancy. Penelitian ini bertujuan untuk mengukur seberapa besar pengaruh kualitas sistem informasi akuntansi manajemen terhadap kualitas informasi akuntansi manajemen. Penelitian ini menggunakan metode survei, bersifat deskriptif dan verifikatif. Unit analisis pada Direktorat Kepegawaian ITB. Analisis data menggunakan persamaan regresi. Hasil penelitian menunjukkan bahwa kualitas sistem informasi akuntansi manajemen berpengaruh pada kualitas informasi akuntansi manajemen besarnya variabilitas kualitas informasi akuntansi manajemen dijelaskan oleh variabel kualitas sistem informasi akuntansi manajemen sebesar 98,6\%.

Kata Kunci: Sistem Informasi Akuntansi; Informasi Akuntansi Manajemen; Akuntansi Manajemen.

Corresponding author. Email. rima.rachmawati@widyatama.ac.id. Jalan Cikutra No. 204 A, Cibeunying Kidul, Bandung, Jawa Barat 40125

How to cite this article. Rachmawati, R. (2016). Sistem Informasi Dilihat dari Aspek Kualitas Informasi Akuntansi Manajemen. Jurnal Riset Akuntansi Dan Keuangan Program Studi Akuntansi Fakultas Pendidikan Ekonomi Dan Bisnis Universitas Pendidikan Indonesia, 4(2), 985-992. Retrieved from http://ejournal.upi.edu/index.php/JRAK/article/view/4032

History of article. Received: Mei 2016, Revision: Juli 2016, Published: Agustus 2016

Online ISSN: 2541-061X. Print ISSN: 2338-1507. DOI : 10.17509/jrak.v4i2.4032

Copyright@2016. Jurnal Riset Akuntansi dan Keuangan Program Studi Akuntansi FPEB UPI 


\section{PENDAHULUAN}

Bagi perusahaan, informasi dipandang sebagai sumber daya bisnis, sama halnya dengan sumber daya bisnis lainnya seperti bahan baku, mesin dan tenaga kerja, informasi tersebut diperlukan untuk mempertahankan kelangsungan hidup perusahaan (Hall, 2013:3). Informasi akuntansi manajemen merupakan hasil dari proses akuntansi manajemen berupa informasi keuangan dan informasi nonkeuangan yang disajikan untuk kepentingan pihak internal perusahaan (Hansen \& Mowen, 2015:9). Informasi akuntansi manajemen berguna bagi para manajer untuk menjalankan fungsi perencanaan, koordinasi, dan pengendalian kegiatan organisasi (Norren, Brewer \& Garrison, 2011:31). Chenhall \& Morris (1986) mengukur kualitas informasi akuntansi manajemen ke dalam dimensi: "broadscope, timelines, aggregation dan integration".

Kebutuhan akan informasi akuntansi manajemen dapat diperoleh melalui Sistem Informasi Akuntansi Manajemen (SIAM) perusahaan (Heidman, 2006:42). Menurut Bouwens \& Abernethy (2000) bahwa "management accounting information system is a formal system designed for providing information to managers". Selanjutnya Hansen \& Mowen (2015:4) menambahkan lebih lanjut bahwa: "management accounting information system is an information system that proceduces output using inputs and process needed to satisfy specific management objectives". Sependapat dengan Cassia et al. (2005) menjelaskan bahwa "management accounting systems as a set of tools involving the activities of information collection, classification and computing in order to help the strategic decision making process".

Pada kenyataannya sistem informasi akuntansi manajemen yang digunakan dalam suatu lembaga masih memiliki permasalahan. Permasalahan yang terkait dengan sistem informasi akuntansi manajemen terjadi di salah satu perguruan tinggi negeri. Seperti yang diungkapkan oleh Encik (Wakil Rektor Bidang Kemahasiswaan Universitas Mulawarman) belum menerapkan sistem informasi secara optimal buktinya program $e$ - learning, e-librabry, mikrotik ecademy, eplan dan program lainnya tidak dikelola dengan serius sehingga tidak ada informasi yang dapat diperoleh oleh pengunjung. Sehingga Universitas ini terlempar jauh dari 100 Besar versi Webometrics, padahal Menurut versi Kemenristekdikti Unmul terbaik se-Kalimantan.

Berdasarkan permasalahan yang terjadi di lapangan dan teori yang digunakan terdapat faktor yang dapat mempengaruhi kualitas informasi akuntansi manajemen yaitu kualitas sistem informasi. Permasalahan dirumuskan: "Seberapa besar pengaruh kualitas sistem informasi terhadap kualitas informasi akuntansi manajemen".

\section{KAJIAN LITERATUR}

\section{Sistem Informasi Akuntansi Manajemen}

Menurut Bagranoff et al., (2010:5) menjelaskan:"accounting information system is a collection of data and processing procedures that creates needed information for its users". Dari pengertian tersebut dapat diartikan bahwa, sistem informasi akuntansi adalah sekumpulan data dan prosedur proses yang membuat informasi yang dibutuhkan oleh penggunannya (Bagranoff et al. 2010:5).

Selanjutnya Heidman (2008:42) menjelaskan bahwa sistem informasi akuntansi manajemen adalah sistem formal yang memberikan informasi dari lingkungan internal dan lingkungan eksternal untuk manajer. Gordon \& Narayaan (1984) menambahkan bahwa sistem informasi akuntansi manajemen didefinisikan sebagai sistem formal yang dirancang untuk menyediakan manajer dengan informasi yang diperlukan untuk memfasilitasi keputusan dan evaluasi kegiatan manajerial. Belkaoui \& Riahi (2010:8) menjelaskan sistem informasi akuntansi manajemen adalah sebagai seperangkat sumber daya manusia dan modal dalam suatu organisasi yang bertanggung jawab untuk produksi dan penyebaran informasi yang dianggap relevan untuk pengambilan keputusan internal.

Berdasarkan uraian di atas, yang dimaksud sistem informasi akuntansi manajemen dalam penelitian ini adalah sistem 
formal yang dirancang untuk menyediakan informasi bagi manajemen yang diperlukan untuk memfasilitasi pengambilan keputusan.

\section{Informasi Akuntansi Manajemen}

Sebelum membahas tentang informasi akuntansi manajemen perlu terlebih dahulu membahas tentang informasi. Menurut Steel \& Al-Hakim (2009:23) "information is factual and its meaning is deciphered through the process of construction, whereby artefacts come into being". Sedangkan lebih detail Bagranoff, Simkin \& Norman (2010:17), menjelaskan informasi akuntansi manajemen memiliki karakteristik meliputi, (1) Focuses on providing accounting information for internal parties, such as management, rather than for external investors and creditor; (2) Mostly forward-looking; (3) Not regulated by generally accepted accounting principle, nor is it mandatory to prepare it; (4) Report include both non-monetary and financial data; (5) Influenced by many business and non-business discipline, such as economics, behavior science and quantitative methods; (6) Flexible and frequently involves nonroutine reporting.

Informasi akuntansi manajemen adalah informasi yang digunakan oleh manajer untuk melakukan perencanaan, pengendalian dan pengambilan keputusan Hoque (2013:4). Agar keputusan yang dimbil oleh manajer sesuai dengan harapan, maka diperlukan informasi yang berkualitas Romney \& Steinbart (2012: 24).

Pernyataan Heidman (2008:46) mendukung pernyataan Hoque (2013) diatas, bahwa informasi akuntansi manajemen mencakup informasi yang disajikan untuk pihak internal atau eksternal, informasi dalam bentuk keuangan maupun nonkeuangan, informasi kuantitatif atau kualitatif.

Berdasarkan definisi yang dikemukakan oleh beberapa pakar diatas maka kualitas informasi akuntansi manajemen yang dimaksud dalam penelitian ini adalah informasi yang digunakan oleh manajer dalam menjalankan fungsinya (perencanaan, pengendalian dan pengambilan keputusan) yang melekat atribut kualitas pada informasi tersebut.

Cecelja (2002:22) menambahkan ciriciri informasi akuntansi manajemen yang berkualitas: tepat waktu dan akurat. Nelson, Todd \& Wixom (2005) menambahkan dimensi kualitas informasi (1) Accuracy, the degree to which information is correct, unambiguous, meaningful, believable, and consistent; (2) Completeness, the degree to which all possible states relevant to the user population are represented in the stored information; (3) Currency, the degree to which information is up-to-date; (4) Format, the degree to which information is presented in a manner that is understandable and interpretabel to the user and thus aids in the completion of a task.

\section{Kerangka Pemikiran}

Hilton \& Platt (2015:7) menambahkan bahwa sistem akuntansi manajemen menyediakan semua jenis informasi manajemen untuk mendukung peran manajemen dalam mengarahkan seluruh kegiatan organisasi, sebagai berikut: "management accounting systems supply all kinds of information to management in support of management role in directing the organization's activities".

Pendapat yang sama dikemukakan oleh (Mia \& Winata, 2005) bahwa, peran sistem informasi akuntansi manajemen dalam memenuhi kebutuhan informasi manajer sebagai komponen utama dari organisasi dan sistem kontrol. Azhar Susanto (2013:12) menambahkan dengan pernyataannya bahwa sistem informasi akuntansi memainkan peranan penting untuk menghasilkan informasi akuntansi manajemen untuk memenuhi fungsi informasi manajemen bagi kepentingan pihak internal perusahaan, yaitu berbagai tingkat pimpinan perusahaan.

Hasil penelitian tentang pengaruh sistem informasi akuntansi manajemen terhadap kualitas informasi akuntansi manajemen disampaikan oleh Lokman (2005) dengan kesimpulan bahwa dengan menggunaan sistem informasi akuntansi manajemen mampu menghasilkan informasi akuntansi 
manajemen sehingga dapat membantu manajer dalam melaksanakan tugasnya.

Pendapat Mia \& Winata dipertegas oleh Atrill \& Mclaney (2006:21) menyatakan bahwa sistem informasi akuntansi manajemen mengidentifikasi dan menangkap informasi yang relevan.

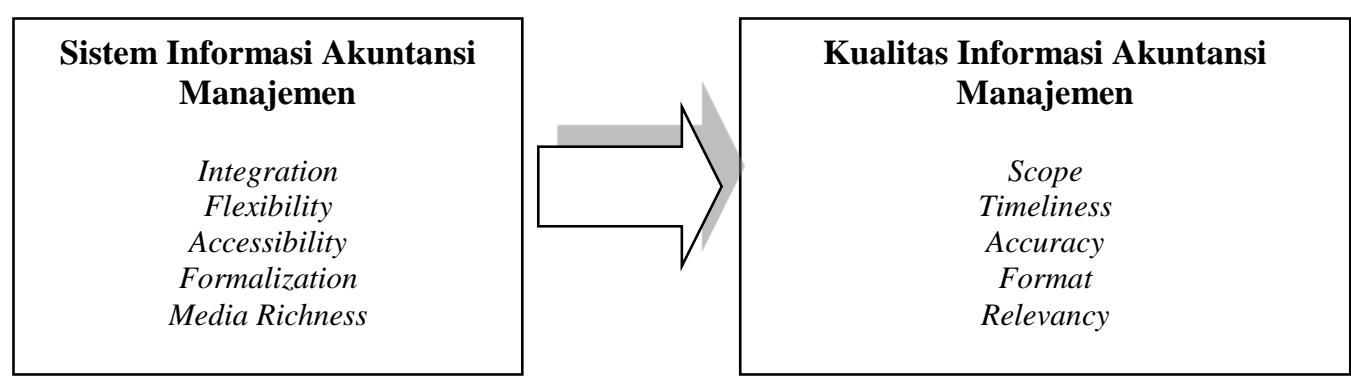

Gambar 1. Paradigma Penelitian

\section{METODOLOGI PENELITIAN}

Metode penelitian pada dasarnya merupakan cara ilmiah untuk mendapatkan data dengan tujuan dan kegunaan tertentu (Sugiyono, 2014:3). Data yang digunakan dalam penelitian ini adalah data kuantitatif yaitu data kualitatif yang diangkakan/ scoring dengan data ordinal serta metode pengumpulan data dengan cara survei. Teknik pengumpulan data jika dilihat dari sumbernya, penelitian ini menggunakan data primer yaitu data (informasi) tangan pertama yang diperoleh dengan menggunakan kuesioner (angket). Statistik nonparametris digunakan untuk melakukan analisis data karena data memiliki jumlah sampel kecil, bersifat data ordinal dan tidak berdistribusi normal (Sugiyono, 2014:221). Penelitian ini akan menguji hubungan kausal yaitu pengaruh variabel independen terhadap variabel dependen. Variabel dependen (variabel yang dipengaruhi) adalah kualitas informasi akuntansi manajemen. Variabel independen (variabel yang mempengaruhi) adalah kualitas sistem informasi akuntansi. Hubungan kausal adalah hubungan yang bersifat sebab akibat.

$$
\begin{aligned}
& \text { Keterangan : } \\
& \alpha=\text { koefisien reliabilitas alpha } \\
& \mathrm{k}=\text { jumlah item } \\
& \mathrm{Sj}=\text { varians responden untuk item I } \\
& \mathrm{Sx}=\text { jumlah varians skor total }
\end{aligned}
$$

Indikator pengukuran reliabilitas menurut Sekaran (2000: 312) yang membagi
Populasi adalah wilayah generalisasi yang terdiri atas obyek/ subyek yang mempunyai kausalitas dan karakteristik tertentu yang ditetapkan oleh peneliti untuk dipelajari dan kemudian ditarik simpulan (Sugiyono, 2014:119). Populasi penelitian ini adalah pengguna sistem informasi akuntansi manajemen pada Direktorat Kepegawaian ITB. Sedangkan sampel penelitian mengacu pada pernyataan Sekaran \& Bougie (2013:241) bahwa "sample is a subset of the population". Teknik penetapan sampel menggunakan nonprobability sampling dengan teknik sampling jenuh. Alasan digunakan teknik ini karena semua anggota populasi digunakan sebagai sampel (Sugiyono, 2014:126). Sampel dalam penelitian ini berjumlah 32 orang.

Pengujian instrumen penelitian terdiri dari uji validitas dan uji reliabilitas. Uji reliabilitas untuk mengukur sejauhmana hasi pengukuran dapat dipercaya. Uji reliabilitas menggunakan rumus alpha $(\alpha)$. Rumus :

$$
\boldsymbol{\alpha}=\frac{k}{k 1} 1 \frac{\sum S^{2} j}{S^{2} x}
$$

tingkatan reliabilitas dengan kriteria sebagai berikut

Jika alpha atau $r$ hitung:
1. $0,8-1,0$
$=$ Reliabilitas baik
2. $0,6-0,799=$ Reliabilitas diterima
3. $<0,6=$ Reliabilitas kurang baik

Validitas adalah suatu ukuran yang 
menunjukkan tingkat-tingkat kevalidan atau kesahihan sesuatu instrumen (Arikunto, 2002: 144). Rumus korelasi product moment yang dikemukakan oleh Pearson dalam Arikunto, (2002: 146) sebagai berikut:

$$
\begin{aligned}
& =\frac{\frac{\left.\sum x y \quad\left\{\sum x\right\} \sum y\right\}}{N}}{\sqrt{\frac{\Sigma x^{2}(\Sigma x)^{2}}{N} \frac{\Sigma y^{2}(\Sigma y)^{2}}{N}}} \\
& \text { dengan pengertian } \\
& \text { rxy : koefisien korelasi antara } \mathrm{x} \text { dan } \\
& \mathrm{y}_{\mathrm{xy}} \\
& \mathrm{N} \text { : Jumlah Subyek } \\
& \mathrm{X} \text { : Skor item } \\
& \mathrm{Y} \text { : Skor total } \\
& \sum X \quad \text { : Jumlah skor items } \\
& \sum \mathrm{Y} \quad \text { : Jumlah skor total } \\
& \sum X^{2} \quad \text { Jumlah kuadrat skor item } \\
& \sum \mathrm{Y}^{2} \text { : Jumlah kuadrat skor total } \\
& \text { (Suharsimi Arikunto, } 2002 \text { : 146) }
\end{aligned}
$$

Teknik analisis data menggunakan persamaan model regresi dinyatakan dalam rumus sebagai berikut:

$$
\mathbf{Y}=\mathbf{a}+\mathbf{X}
$$

Keterangan:

$\mathrm{Y}=$ Variabel dependen

$\mathrm{X}=$ Variabel independen

$\mathrm{a}=$ konstanta regresi

\section{HASIL DAN PEMBAHASAN}

Objek penelitian ini adalah sistem informasi akuntansi manajemen dan kualitas informasi akuntansi manajemen. Variabel independen adalah kualitas sistem informasi akuntansi manajemen sedangkan variabel dependen adalah kualitas informasi akuntansi manajemen.

Direktorat Kepegawaian ITB digunakan sebagai subjek penelitian. Direktorat Kepegawaian ditetapkan berdasarkan Keputusan Rektor ITB Nomor 147/SK/K01/OT/2010 tanggal 21 April 2010. Sesuai dengan tugas pokok dan fungsi yang menjadi tanggung jawabnya, Direktorat
Kepegawaian melaksanakan administrasi kepegawaian mulai dari penerimaan pegawai, penempatan (promosi/demosi/mutasi), dan pemberhentian pegawai. Selain itu Direktorat Kepegawaian melaksanakan tugas-tugas yang berkaitan dengan remunerasi dan kesejahteraan pegawai yang meliputi pembayaran gaji, tunjangan, insentif, pembayaran uang lembur, uang makan dan transport serta asuransi jiwa dan asuransi rawat inap bagi seluruh pegawai ITB.

Secara garis besar kebijakan pengembangan bidang Sumber Daya Manusia (SDM) ITB dinyatakan dalam Renstra ITB dengan sasaran pada tahun 2010 yaitu (1) Tersedianya SDM yang kompeten menjalankan program akademik dan pendukungnya; (2) Tersedianya sistem manajemen SDM berbasis kompetensi dan meritokrasi yang mendukung iklim penelitian dan pengabdian kepada masyarakat.

Kedua hal tersebut merupakan suatu kesatuan yang saling mempengaruhi. Untuk itu akan dibangun sistem dan ketentuan yang memungkinkan dicapainya kedua hal tersebut. Adapun tugas dan tanggung jawab pada Sub Direktorat Remunerasi dan Kesejahteraan meliputi (1) Mengusulkan Rencana Kerja Sub Direktorat Remunerasi dan Kesejahteraan yang selaras dengan RKAP; Mengkoordinasi kegiatan pengendalian aliran dana dengan memonitor realisasi penerimaan dan pengeluaran, memonitor ketersediaan dana dan mengusahakan kekurangan kebutuhan dana; (3) Mengotorisasi berkas pembayaran untuk dilakukan legalisasi; (4) Menganalisa kode Cash Flow terhadap BKK/BKM; (5) Mengotorisasi Berkas Penerimaan untuk dilakukan legalisasi.

Analisis verifikatif bertujuan mengetahui hubungan antar variabel melalui pengujian hipotesis dengan menggunakan regresi. Sebelum diuji regresi dilakukan terlebih dahulu validitas dan reliabilitas dan kedua variabel dinyatakan valid dan reliable. Langkah selanjutnya menguji dengan persamaan regresi dan menggunakan SPSS untuk mengolah data. 
Tabel 1. Model Summary

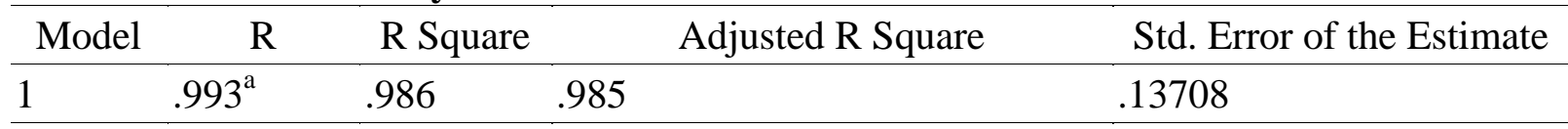

a. Predictors: (Constant), Y

Berdasarkan Tabel 1 dapat menggambarkan derajat keeratan hubungan antar variabel.

Angka R sebesar 0.993(a) menunjukkan bahwa korelasi/hubungan antara informasi akuntansi dengan variabel independen-nya adalah kuat (karena besarnya $>0,5$ ).

Angka R Square atau Koefisien Determinasi adalah 0.986. Ini artinya bahwa 0,986 atau 98,6\% variasi dari informasi akuntansi manajemen dapat dijelaskan oleh variasi dari variabel independennya yaitu kualitas sistem informasi.
Menurut (Hair et al., 2014:186) jika nilai $\mathrm{R}^{2}$ lebih besar dari $67 \%$ berada dalam kategori substansial, hal ini dapat diinterpretasikan bahwa variabilitas kualitas informasi akuntansi manajemen substantial dibentuk oleh kualitas sistem informasi akuntansi manajemen.

Std. Error of the Estimate yang nilainya 0.13708 menggambarkan tingkat ketepatan prediksi regresi, dimana semakin kecil angkanya maka semakin baik prediksinya.

Tabel 2. Coefficients ${ }^{\mathrm{a}}$

\begin{tabular}{|c|c|c|c|c|c|c|c|}
\hline & \multirow[t]{2}{*}{ Model } & \multicolumn{2}{|c|}{$\begin{array}{c}\text { Unstandardized } \\
\text { Coefficients }\end{array}$} & \multicolumn{2}{|c|}{$\begin{array}{l}\text { Standardized } \\
\text { Coefficients }\end{array}$} & \multirow[b]{2}{*}{ Sig. } & \multirow{2}{*}{$\begin{array}{l}95.0 \% \text { Confidence Interval } \\
\text { for B } \\
\text { Lower Bound Upper Bound }\end{array}$} \\
\hline & & B & Std. Error & Beta & $\mathrm{T}$ & & \\
\hline \multirow[t]{2}{*}{1} & (Constant) & .040 & .076 & & .530 & .600 & -.114 \\
\hline & Y & .964 & .021 & .993 & 46.416 & .000 & 1.006 \\
\hline
\end{tabular}

a. Dependent Variable: $\mathrm{X}$

Tabel 2 dapat dijelaskan bahwa persamaan regresi yang dihasilkan adalah (1) Kualitas informasi akuntansi manajemen $=0,04+$ 0,964 kualitas sistem informasi akuntansi; (2) Konstanta 0,04 menyatakan bahwa jika tidak ada peningkatan kualitas sistem informasi akuntansi maka kualitas informasi akuntansi manajemen 0,04; (3) Koefisien regresi 0,964 menunjukkan bahwa setiap adanya kenaikan satu satuan simpangan baku kualitas sistem informasi akuntansi maka kualitas informasi akuntansi manajemen akan bertambah sebesar 0,964 simpangan baku; (4) Sedangkan uji-t digunakan untuk menguji signifikansi atas hipotesis yang dibangun. Hipotesis yang diajukan:

$\begin{array}{ll}\mathrm{H}_{0}=0 & \begin{array}{l}\text { kualitas sistem informasi } \\ \text { akuntansi manajemen tidak } \\ \text { berpengaruh terhadap kualitas } \\ \text { informasi } \\ \text { manajemen. akuntansi } \\ \text { kualitas sistem informasi }\end{array}\end{array}$

akuntansi manajemen berpengaruh terhadap kualitas informasi akuntansi manajemen.

Statistik uji yang digunakan adalah:

$$
t=\frac{\beta}{S E(\beta)}
$$

Kriteria Uji : tolak $H_{0}$ jika nilai-P(Sig) lebih kecil dari taraf signifikansi $=0,05$

Berdasarkan table 2, nilai-p lebih kecil dari pada 0,05 maka $\mathrm{H}_{0}$ ditolak. Berarti kualitas sistem informasi akuntansi manajemen berpengaruh terhadap kualitas informasi akuntansi manajemen.

Berdasarkan observasi selama penelitian dilakukan diperoleh informasi bahwa aplikasi sistem informasi akuntansi manajemen yang digunakan oleh unit analisis antara lain adalah oracle finance, sisfo, excel, world, saiba, e$s p t$, siskeu. Penggunaan aplikasi sistem 
informasi untuk berbagai keperluan sesuai dengan kebutuhan pengguna antara lain untuk melakukan (1) Penyusunan laporan keuangan; (2) Pengajuan gaji dan data gaji; (3) Input payment pajak; (4) Tarik data transfer dari keuangan; (5) Pergudangan, penerimaan baran, pengadaan barang, input harga barang; (6) Rencana implementasi anggaran; (7) Kalkulasi pajak untuk setiap kegiatan; (8) Monitoring laporan unit, bahan, verifikasi referensi anggaran; (9) Menghitung penyusutan; (10) Laporan Pajak.

\section{SIMPULAN}

Berdasarkan fenomena, rumusan masalah, hipotesis dan hasil penelitian maka penulis menarik simpulan bahwa kualitas sistem informasi akuntansi manajemen berpengaruh terhadap kualitas informasi akuntansi manajemen pada Direktorat Kepegawaian ITB. Sistem informasi akuntansi manajemen menunjukkan kontribusi yang tinggi terhadap kualitas informasi akuntansi manajemen. Informasi akuntansi manajemen yang belum berkualitas dikarenakan belum terintegrasinya data antara bagian satu dengan bagian lainnya dalam fungsi yang sama maupun dalam fungsi yang berbeda. Meningkatkan kualitas sistem informasi akuntansi manajemen dengan beberapa cara, yaitu (1) Melengkapi aplikasi sistem informasi akuntansi manajemen dengan fasilitas-fasilitas sehingga sistem memiliki kemampuan accessibility yang dapat membantu pengguna untuk menggunakan sistem informasi dimana dan kapanpun mereka berada; (2) Melengkapi sistem informasi akuntansi manajemen dengan fasilitas penyimpanan data dan pemeliharan data seperti fasilitas mengumpulkan data ke dalam beberapa kategori, menggandakan data ke beberapa dokumen, memilah data berdasarkan beberapa karakteristik, penyimpanan data (storing) serta fasilitas membuka data untuk melakukan suatu proses atau mengirim laporan kepada user.

\section{DAFTAR PUSTAKA}

Atriil, P., \& McLaney, E. 2006. Accounting and Finance. England: Prentice Hall.

Azhar Susanto. 2013. Sistem Informasi Akuntansi, Struktur Pengendalian Risiko Pengembangan. Bandung: Lingga Jaya. .2013. Sistem Informasi Manajemen (Konsep dan Pengembangan). Bandung: Lingga Jaya.

Bagranoff, N. A., Simkin, M. G., \& Norman, C. S. 2010. Accounting Information Systems (Elevanth ed.). USA: John Wiley \& Sons.

Belkaoui \& Riahi, A. 2010. Behavior Management Accounting. USA: Quarumbooks.

Bouwens, J., \& Abernethy, M. A. 2000. The Consequences of Customizationon Management Accounting System Design. Accounting Organizations and Society, 221-241.

Cassia, L., Paleari, S., \& Redondi, R. 2005. Management Accounting Systems and Organizational Structure. Sources Small Business Economics , 25 (4), 373-391.

Cecelja, F. 2002. Manufacturing Information \& Data Systems. London: Penton Press.

Chenhall, R. H., \& Morris, D. 1986. The impact of structure, environment and interdependence on the perceived usefulness of management accounting systems,. The Accounting Review , 61 (1), 16-35.

Encik. 2016. Sayangnya, Diberi Dana Besar tapi Website Fakultas Cuma Pajangan. Melalui http://www.kaltim.prokal.co/read/news [14/8/2016,16:45].

Gordon, L., \& Miller, D. 1976. A Contingency Framework for the design of Accounting Information Systems. Vol. 1 No. 1, pp 59-69.

Gordon, L., \& Narayan. V. 1984. Management Accounting Systems Perceived Environmental Uncertainty and Organization Structure. Empirical 
Investigation and Society, 9 (1), 3347.

Hall, James. A. 2013. Introduction to Accounting Information Systems (8th ed.). South-Western: Cengage Learning.

Hair Jr, J. F., Mult, T., Ringle, C., \& Sarstedt, M. 2014. A Primer on Partial Least Squares Structural Equation Modeling (PLS-SEM).

USA: $\quad$ SAGE Publications.

Hansen, D. R., Mowen, M. M., \& Guan, L. 2015. Cost Management (Accounting $\&$ Control) (Sixth ed.). Canada: Cengage Learning.

Heidman, M. 2008. The Role of Management Accounting Systems in Strategic Sensemaking. German: Deutscher Universiti_Verlag.

Heidman, Marcus, Schaffer, U., \& Strahringer, S.2006. Exploring the Role of Management Accounting Systems in Strategic Sensemaking. In Information Systems Management (pp. Pp: 244-257).

Hilton, R. W. 2008. Managerial Accounting Creating Value a Dynamic Business Environment (Seventh ed.). New York: McGraw-Hill.

Hilton, R. W., \& Platt, D. E. 2015. Managerial Accounting (Tenth ed.). New York: McGraw-Hill.

Hoque, Zahirul. 2013. Strategic Management Accounting:Concept, process and issues. (Second ed.). Biddles:UK: Great Britain.

Lokman, M., \& Lokman, W. 2005. Manufacturing Strategy, Broad scope MAS Information and Information Communication Technology. Research Note

Mia, L., \& Winata, L. 2005. Manufacturing Strategy, Broad scope MAS Information and Communication Technology.

Nelson, R. R., Todd, P. A., \& Wixom, B. H. 2005. Antecedents of Information and System Quality: An empirical examination within the context of data warehousing. Journal of Management Information Systems , 21 (4), 199-235.

Norren, E., Brewer, P., \& Garrison, R. 2011. Managerial Accounting for Managers. New York: McGraw-Hill.

Sekaran, Uma., \& Bougie, Roger. 2013. Research Methods for Business (Sixth Edition ed.). UK: John Wiley.

Steel, A. C., \& Al-Hakim, L. 2009. Information Systems, Research Methods, Epistemology and Applications. New York: h.

Sugiyono. 2014. Metode Penelitian Kombinasi. Bandung: Alfabeta. 